\title{
Variation in zoogeographical composition along an elevational gradient: the tenebrionid beetles of Latium (Central Italy)
}

\section{S. Fattorini}

\author{
Azorean Biodiversity Group and Platform for Enhancing Ecological Research \& Sustainability, \\ Department of Ciências Agrárias, University of Açores, Angra do Heroísmo, Terceira, Açores, \\ Portugal; Water Ecology Team, Department of Biotechnology and Biosciences, University of \\ Milano Bicocca, Milan, Italy
}

\begin{abstract}
The aim of this paper is to propose the use of chorotype analysis of species assemblages on an elevational gradient to detect the main historical and ecological factors responsible for current faunal settings. A comprehensive faunistic database was used to assess species abundance across $100 \mathrm{~m}$ belts in Latium (Central Italy). Species were assigned to chorotypes according to their ranges. Entropy and evenness indices were applied to both species abundances and chorotype frequencies recorded in each belt. Both species and chorotype entropy decreased with elevation, whereas species and chorotype evenness increased. Chorotypes centred on the Mediterranean basin decreased with increasing elevation, chorotypes centred in Europe and Asia had similar frequencies among belts and endemic species increased with elevation. A cluster analysis with species presence/absence data, revealed three main clusters grouping respectively: i) all belts above $1700 \mathrm{~m}$; ii) belts between 901 and $1500 \mathrm{~m}$; and iii) belts between 0 and $900 \mathrm{~m}$. An analysis based on chorotype frequencies produced very similar results. We can conclude that: high elevation assemblages are less diversified, but more balanced than lowland assemblages, in terms of
\end{abstract}

Correspondence: Simone Fattorini, Azorean Biodiversity Group and Platform for Enhancing Ecological Research \& Sustainability (PEERS), Universidade dos Açores, Departamento de Ciências Agrárias, Angra do Heroísmo, Terceira, Açores, Portugal; Water Ecology Team, Department of Biotechnology and Biosciences, University of Milano Bicocca, Milan, Italy. E-mail: simone_fattorini@virgilio.it

Key words: Chorotypes, Coleoptera Tenebrionidae, Diversity, Elevation, Mediterranean, Mountain biogeography, Pleistocene glaciations, Zoogeographical composition.

Received for publication: 9 April 2013.

Revision received: 14 August 2013.

Accepted for publication: 14 August 2013.

This work is licensed under a Creative Commons Attribution NonCommercial 3.0 License (CC BY-NC 3.0).

CC Copyright S. Fattorini, 2013

Licensee PAGEPress, Italy

Entomologia 2013; 1:e6

doi:10.4081/entomologia.2013.e6 both species and chorological composition. Belts similar in species composition (presence/absence) are also similar in zoogeographical composition (frequency of chorotypes). This indicates that elevation is a factor that strongly selects species' attributes and especially their geographical distribution. Variations in chorotype composition along an elevational gradient may be used to trace the history of biotas.

\section{Introduction}

Each species has its own geographical distribution. However, recurrent similar ranges can be grouped into a limited number of idealized categories, which are frequently referred to as chorotypes (Vigna Taglianti et al., 1999; Olivero et al., 2011). Chorotype analysis makes it possible to compare the biogeographical composition of different species assemblages, and has been used both in the past and even recently by a large number of zoologists and botanists to characterize local faunas or floras, or species assemblages in a community. However, the interpretation of chorotype analyses is hampered by the fact that two species may show similar distributions, and hence share the same chorotype, because of a variety of reasons, such as common history, similar ecological needs, stochastic events, and research bias (Zunino \& Zullini, 1995).

In general, if two species have similar distributions, i.e. they roughly occupy the same geographical areas, it is assumed that they can tolerate the same main ecological constraints and have similar macroecological needs (Olivero et al., 2011). Thus, a chorotype can be viewed as a biological feature synthesizing the adaptive and evolutionary pathways of a species (Pizzolotto, 2009).

The linkage between spatial distribution and species' macroecology offers the possibility of using chorotype composition of local species assemblages to draw inference about the main ecological and historical factors that shaped such assemblages. For example, the occurrence of species with Arctic distributions on the Alps, or that of species with Boreo-Alpine distribution on the Apennines, is evidence of Pleistocene glacial colonization (Mani, 1968).

Here I put forward the idea of using chorotype composition of species assemblages along an elevational gradient to detect the main historical and ecological factors responsible for current faunal settings. In this approach, each chorotype is a species attribute bearing important pieces of information. In particular, if we can expect that a certain faunal assemblage will invariably show a high percentage of species with chorotypes consistent with the geographical location of the study area 
(e.g. an obvious prevalence of Mediterranean chorotypes in a species assemblage of a Mediterranean area), the occurrence of species with chorotypes centred out of the study area (e.g. the presence of European chorotypes in the same Mediterranean area) may disclose the influence of historical factors and particular current ecological settings.

As an example of this approach, I analyse in this paper the distribution of tenebrionid beetles (Coleoptera Tenebrionidae) in Latium (Central Italy) to show how chorotype composition of insect assemblages varies along an elevation gradient and which biogeographical inferences can be drawn.

\section{Materials and Methods}

\section{Study area}

Latium is situated in the central part of the Italian peninsula. It comprises a land area of nearly $17,200 \mathrm{~km}^{2}$, mostly occupied by flat and hilly landscapes interrupted by mountain chains that can surpass $2000 \mathrm{~m}$ elevation (maximum elevation: $2458 \mathrm{~m}$ ). The coast of Latium is mainly composed of sandy beaches and the central section of the region is occupied by a vast alluvial plain. The climate is Mediterranean, but with strong variation according to the elevation: along the coasts, monthly average temperatures are comprised between $9-10^{\circ} \mathrm{C}$ in January and $24-25^{\circ} \mathrm{C}$ in July, whereas in the inner (mountainous) areas temperatures may be below $0^{\circ} \mathrm{C}$ in January $\left(-3^{\circ} \mathrm{C}\right.$ on Mount Terminillo) and below $20^{\circ} \mathrm{C}$ in July. Annual precipitation ranges between $700 \mathrm{~mm}$ along the coastal rim and $1200 \mathrm{~mm}$ in the internal mountain areas, being strongly influenced by elevation (Salvati et al., 2012).

\section{Data sources}

I compiled 3561 tenebrionid records from Latium, from which 84 native species are currently known (note that one record refers to a unique combination of species, place, elevation, year and source, but may involve from one to several hundreds of specimens). Data originate from museum and private collections, publications and unpublished lists, for a total of 26,743 specimens (25,349 specimens directly examined, plus literature data for 1394 specimens). The database included the following entries: species name, sampling site, elevation, date, collector(s), number of specimens, collection, reference(s). Sample sites were georeferenced (latitude and longitude decimal degrees) with the maximum precision allowed by the original datum using digital topographic maps. Tenebrionids include certain cosmopolitan species, such as Alphitophagus bifasciatus, Gnathocerus cornutus, Latheticus oryzae, Tenebrio molitor, Tribolium castaneum, Tribolium confusum, and Alphitobius diaperinus, which are associated with stored food. Entomologists rarely collect these species because they are common pests and their occurrence was not considered in the analyses.

Data spanned from 1860 to 2011 . The very large sampling effort made over more than a century by hundreds of collectors interested in different insect groups and who used any kind of collecting method (hand searching, pitfall traps, light traps, aerial traps, and soil examination) ensures that these data collectively form a random sampling, not affected by bias due to collector preferences for certain biotopes, sites or species. Also, these beetles are frequently collected by amateur entomologists interested in beetles or insects in general, or as a byproduct of generalized collecting activities performed by entomologists mostly interested in other groups. It is therefore unlikely that amateurs under-collected common species and over-collected rare species. Thus, as a measure of species abundance in each belt, I used the total number of collected specimens. To assess whether the number of collected specimens was biased by collection techniques, I performed a correlation analysis with data obtained from pitfall traps, which are widely used to obtain standardized quantitative data for ground-dwelling insects (Samways et al., 2010). From the database I was able to recover pitfall trap data for 17 tenebrionid species. For these species, abundance data obtained only from pitfall traps resulted strongly correlated with the total number of collected specimens excluding those obtained by pitfall traps (Spearman rank correlation coefficient $r_{s}=0.623$, $\mathrm{P}=0.008$ ). This correlation indicates that the use of the total number of specimens is a good measure for population size, at least analogous to what can be obtained by standardized techniques. Details about the database can be found in Fattorini (2013).

Species' vertical distributions were assessed integrating two pieces of information. When available from the label data or explicitly given in literature records, elevation was included in the database as recorded by the collector (probably using a barometric altimeter or topographic maps). When elevation was not reported among label data or not given in the literature sources, it was retrieved by overlapping point records with topographic maps at the best available resolution. The study area stretches over a relatively small latitudinal range (from $42^{\circ} 50^{\prime} \mathrm{N}$ to $41^{\circ} 20^{\prime} \mathrm{S}$ ), thus minimising any possible effect of a latitudinal gradient. Nomenclature follows Löbl \& Smetana (2008). Because the dividing line between species and subspecies, as applied to tenebrionids, is arguably arbitrary, I considered both systematic levels, but hereon the term species will be used also for subspecies for simplicity.

\section{Elevational subdivision}

In order to explore the basic relationship between elevation and tenebrionid assemblage composition, the gradient was divided into 24 belts of $100 \mathrm{~m}(0-100 \mathrm{~m}, 101-200 \mathrm{~m}, 201-300 \mathrm{~m}$, and so on). I assumed that the elevational ranges of species were continuous; i.e. that each species was present at all elevations between its maximum and minimum elevations, as currently done in most research on elevational gradients, because gaps in recorded distribution at this scale are more likely attributable to sampling incompleteness rather than to true gaps in the distribution of species (Rahbek, 1997; Grytnes \& Vetaas, 2002; Mena \& Vázquez-Domínguez, 2005; Rowe, 2009; Wu et al., 2012). Only for Asida pirazzolii I maintained gaps relative to certain belts because of the peculiar elevational distribution of the subspecies of this species; the lack of the subspecies pirazzolii in a certain belt might be due to replacement with the ssp. sardiniensis. Actually, individuals with transitional characters between the two subspecies occur in certain areas.

Diversity indexes based on species abundances were inevitably based only on observed data. Thus, for application of such indices I considered only documented species abundance in each belt, instead of interpolating species presences between maximum and minimum elevation. This poses, however, the problem of false absences: the lack of records from belts within species elevational ranges may be real (i.e. the species really did not occur in a certain belt) or spurious (i.e. the species did occur in the belt, but was not found). I found that values of observed species richness were strictly correlated with those obtained from interpolated presences (Spearman rank correlation $r_{\mathrm{s}}=0.951, \mathrm{P}<0.0001$ ). This suggests that all belts were adequately surveyed and that the effect of undetected species on the general patterns is negligible.

\section{Elevational gradients in species diversity}

On the basis of the extensive review of diversity indexes performed by Hayek \& Buzas (2010), both Shannon entropy and Buzas and Gibson's evenness were calculated for each elevational belt. Shannon entropy was calculated as:

$$
H=-\sum \frac{n_{i}}{n} \ln \left(\frac{n_{i}}{n}\right)
$$

where $n_{i}$ is number of individuals of taxon $i$, and $n$ was the total num- 
ber of individuals of all taxa. $H$ ranges from 0 (one taxon dominates the community completely) to high values for communities with many taxa, each with few individuals. Buzas and Gibson's evenness is expressed as $E=e^{H} / S$ (where $S$ is the number of species). These two measures are particularly effective in encapsulating many aspects of diversity into a single value and are the least biased by differences in species richness and sampling efforts (Hayek \& Buzas, 2010).

\section{Elevational gradients in chorotype frequencies}

I assigned each species to a chorotype using the scheme presented in Vigna Taglianti et al. (1999; Table 1). Chorotype assignment was based on current information on species distribution as given in Fattorini (2002b, 2005), Fattorini \& Maltzeff (2001) and Aliquò et al. (2006). Then, I used chorotype distribution in each elevation belt to calculate the same diversity indices described above. In these analyses, chorotype abun-

Table 1. Elevational distribution of tenebrionid beetles in Latium (100-m belts) and their chorotypes.

\begin{tabular}{|c|c|c|c|c|c|c|c|}
\hline Species & Chorotype & $\begin{array}{l}\text { Minimum } \\
\text { belt (m) }\end{array}$ & $\begin{array}{l}\text { Maximum } \\
\text { belt (m) }\end{array}$ & Species & Chorotype & $\begin{array}{l}\text { Minimum } \\
\text { belt (m) }\end{array}$ & $\begin{array}{l}\text { Maximum } \\
\text { belt (m) }\end{array}$ \\
\hline Accanthopus velikensis & SEU & $0-100$ & $1101-1200$ & Helops rossii & EME & $0-100$ & $701-800$ \\
\hline Akis bacarozzo & WME & $0-100$ & $901-1000$ & Iphthiminus italicus italicus & EME & $0-100$ & $1401-1500$ \\
\hline Akis italica & NAF & $0-100$ & $201-300$ & Leichenum pulchellum pulchellum & MED & $0-100$ & $0-100$ \\
\hline Allophylax picipes picipes & WME & $0-100$ & $401-500$ & Leptoderis collaris & WME & $0-100$ & $0-100$ \\
\hline Ammobius rufus & MED & $0-100$ & $0-100$ & Lyphia tetraphylla & SEU & $0-100$ & $0-100$ \\
\hline Asida bayardi & END & $0-100$ & $1501-1600$ & Melanimon tibialis & CEM & $0-100$ & $0-100$ \\
\hline Asida luigionii luigionii & END & $0-100$ & $1201-1300$ & Menephilus cylindricus cylindricus & SEU & $0-100$ & $0-100$ \\
\hline Asida pirazzolii pirazzolii & END & $601-700$ & $2301-2400$ & Nalassus aemulus aemulus & WME & $0-100$ & $0-100$ \\
\hline Asida pirazzolii sardiniensis & END & $0-100$ & $2101-2200$ & Nalassus assimilis & WME & $0-100$ & $0-100$ \\
\hline Asida sabulosa & SEU & $0-100$ & $2101-2200$ & Nalassus dryadophilus & SEU & $0-100$ & $801-900$ \\
\hline Blaps gibba & SEU & $0-100$ & $901-1000$ & Nalassus planipennis & END & $0-100$ & $901-1000$ \\
\hline Blaps gigas & MED & $0-100$ & $201-300$ & Neatus noctivagus & EME & $0-100$ & $0-100$ \\
\hline Blaps lethifera lethifera & EUR & $0-100$ & $701-800$ & Neomida haemorrhoidalis & EUR & $0-100$ & $901-1000$ \\
\hline Blaps mucronata & SEU & $0-100$ & $501-600$ & Oochrotus unicolor ardoini & WME & $0-100$ & $601-700$ \\
\hline Bolitophagus interruptus & SEU & $301-400$ & $801-900$ & Opatrum sabulosum sabulosum & SIE & $1001-1100$ & $1001-1100$ \\
\hline Bolitophagus reticulatus & SIE & $0-100$ & $1501-1600$ & Opatrum sabulosum sculptum & SEU & $0-100$ & $1301-1400$ \\
\hline Catomus rotundicollis & WME & $0-100$ & $701-800$ & Pachychila frioli & MED & $0-100$ & $0-100$ \\
\hline Cheirodes sardous & MED & $0-100$ & & Palorus depressus & SIE & $0-100$ & $601-700$ \\
\hline Cnemeplatia atropos atropos & TEM & $0-100$ & $401-500$ & Pedinus meridianus & SEU & $0-100$ & $2101-2200$ \\
\hline Colpotus strigosus ganglbaueri & END & $901-1000$ & $1801-1900$ & Pentaphyllus chrysomeloides & SEU & $0-100$ & $401-500$ \\
\hline Colpotus strigosus strigosus & END & $0-100$ & $1301-1400$ & Pentaphyllus testaceus & SEU & $0-100$ & $101-200$ \\
\hline Corticeus bicolor & SIE & $0-100$ & $701-800$ & Phaleria acuminata & MED & $0-100$ & $0-100$ \\
\hline Corticeus fasciatus & EUR & $0-100$ & $0-100$ & Phaleria bimaculata bimaculata & WME & $0-100$ & $0-100$ \\
\hline Corticeus pini & SIE & $0-100$ & $0-100$ & Phaleria provincialis ghidinii & END & $0-100$ & $101-200$ \\
\hline Corticeus unicolor & EUR & $0-100$ & $1601-1700$ & Phtora crenata & WME & $0-100$ & $0-100$ \\
\hline Cossyphus tauricus & TUM & $0-100$ & $401-500$ & Phylan abbreviatus italicus & END & $0-100$ & $501-600$ \\
\hline Crypticus gibbulus & MED & $0-100$ & $0-100$ & Pimelia bipunctata & WME & $0-100$ & $0-100$ \\
\hline Crypticus quisquilius aprutianus & END & $301-400$ & $1501-1600$ & Platydema europaea & SEU & $0-100$ & $0-100$ \\
\hline Dendarus coarticollis & WME & $0-100$ & $701-800$ & Platydema violacea & SEU & $0-100$ & $1001-1100$ \\
\hline Dendarus lugens & WME & $0-100$ & $701-800$ & Pseudoseriscius normandi pacificii & END & $0-100$ & $0-100$ \\
\hline Diaclina testudinea & SEU & $0-100$ & $0-100$ & Scaphidema metallica & EUR & $0-100$ & $901-1000$ \\
\hline Diaperis boleti & SIE & $0-100$ & $1001-1100$ & Scaurus striatus & WME & $0-100$ & $401-500$ \\
\hline Dichillus minutus & SEU & $0-100$ & $601-700$ & Stenomax lanipes & WME & $201-300$ & $1701-1800$ \\
\hline Eledona agricola & OLA & $0-100$ & $1401-1500$ & Stenosis brenthoides brenthoides & SEU & $0-100$ & $301-400$ \\
\hline Erodius siculus neapolitanus & END & $0-100$ & $0-100$ & Stenosis intermedia & SEU & $0-100$ & $0-100$ \\
\hline Gonocephalum assimile & END & $0-100$ & $0-100$ & Stenosis sardoa & WME & $0-100$ & $301-400$ \\
\hline Gonocephalum granulatum nigrum & TEM & $0-100$ & $701-800$ & Tentyria grossa grossa & WME & $0-100$ & $301-400$ \\
\hline Gonocephalum obscurum obscurum & $m$ WME & $0-100$ & $0-100$ & Tentyria italica & SEU & $0-100$ & $401-500$ \\
\hline Gonocephalum rusticum & MED & $0-100$ & $301-400$ & Trachyscelis aphodioides & MED & $0-100$ & $0-100$ \\
\hline Gunarus parvulus & WME & $0-100$ & $0-100$ & Uloma culinaris & SIE & $0-100$ & $401-500$ \\
\hline Halammobia pellucida & MED & $0-100$ & $0-100$ & Xanthomus pallidus & WME & $0-100$ & $0-100$ \\
\hline Helops caeruleus & EUR & $0-100$ & $2101-2200$ & Xanthomus pellucidus & MED & $0-100$ & $0-100$ \\
\hline
\end{tabular}

Chorotype abbreviations: NAF: N-African, CEM: Centro-European-Mediterranean, EME: E-Mediterranean, EUR: European, MED: Mediterranean, OLA: Holarctic, SEU: S-European, SIE: Sibero-European, TEM: TuranianEuropean-Mediterranean, TUM: Turanian-Mediterranean, WME= W-Mediterranean. Apennine endemics are indicated with END. 
dances were the number of species belonging to each chorotype.

Chorotypes were also grouped into two wider categories: southern chorotypes (species with AFR, WME, EME, MED, TEM, TUM, and CEM chorotypes) and northern chorotypes (species with SEU, EUR, SIE, and OLA chorotypes). Percent frequencies of these categories were correlated with elevation using Spearman rank correlation tests. Calculations were done with the software STATISTICA 7 (StatSoft 2004).

\section{Similarity in species and chorotype composition}

There is a long debate about the most appropriate index to express biotic similarity. I used Simpson's similarity coefficient for species absence/presence data because it is independent of species richness gradients (Koleff et al., 2003) and thus accounts only for spatial turnover (species replacement) and excludes the effect of dissimilarity due to nestedness (Baselga, 2010, 2012).

To obtain an overall representation of faunal turnover among all elevational belts, I used pairwise values of Simpson's similarity. This similarity matrix was then used to aggregate belts into clusters using the UPGMA as an amalgamation rule, because it is considered the clustering strategy that minimizes distortion of the original data matrix and it is therefore particularly favoured in biogeographical studies (e.g. Shi, 1993; Fattorini, 2002a).

To compare belts on the basis of chorotypes frequency, I used Morisita's index, which is nearly independent of sample size and diversity (Krebs, 1989). Analyses were performed using the software PAST v. 2.17 (Hammer et al., 2001). Correlation between matrices of inter-belt similarity values based on species composition (Simpson's index) and inter-belt similarity values based on chorotype frequency (Morisita's index) was tested using a non-parametric (Spearman correlation, $r_{\mathrm{s}}$ )
Mantel test with 10,000 permutations using the software XLSTAT 7.5.2 (Addinsoft, 2004).

\section{Results}

Species richness had a sharp decline with elevation, being particularly low over $1000 \mathrm{~m}\left(r_{\mathrm{s}}=-0.934, \mathrm{P}<0.0000001\right.$; Figure 1). Species entropy and evenness tended to have opposite trends: entropy decreased with elevation $\left(r_{\mathrm{s}}=-0.840, \mathrm{P}=0.0000003\right)$, whereas evenness increased $\left(r_{\mathrm{s}}=0.752, \mathrm{P}=0.00002\right)$. Similarly, chorotype entropy decreased with elevation $\left(r_{\mathrm{s}}=-0.965, \mathrm{P}<0.0000001\right)$ and evenness increased $\left(r_{\mathrm{s}}=-0.913, \mathrm{P}<0.0000001\right)$. Thus chorotypes entropy and evenness showed patterns consistent with those highlighted by species (Figure 2; Spearman rank correlation between species and chorotype entropy $r_{\mathrm{s}}=0.799, \mathrm{P}=0.000003$; Spearman rank correlation between species and chorotype evenness $r_{\mathrm{s}}=0.679, \mathrm{P}=0.000265$ ).

Chorological composition varies considerably among elevational belts (Figure 3): i) chorotypes centred on the Mediterranean basin (southern chorotypes) decreased in their relative frequency with increasing elevation $\left(r_{\mathrm{s}}=-0.880, \mathrm{P}<0.0000001\right)$; ii) chorotypes centred in Europe and Asia showed similar proportions among belts $\left(r_{\mathrm{s}}=-0.141, \mathrm{P}=0.511\right)$; and iii) frequency of endemic species increased with elevation $\left(r_{\mathrm{s}}=0.947, \mathrm{P}<0.0000001\right)$.

A cluster analysis, which considered variation in species composition among belts, revealed three main clusters, corresponding to sharp reductions in Simpson's similarity (Figure 4a). A first cluster is represented by the separation of all belts above $1700 \mathrm{~m}$, which have faunas

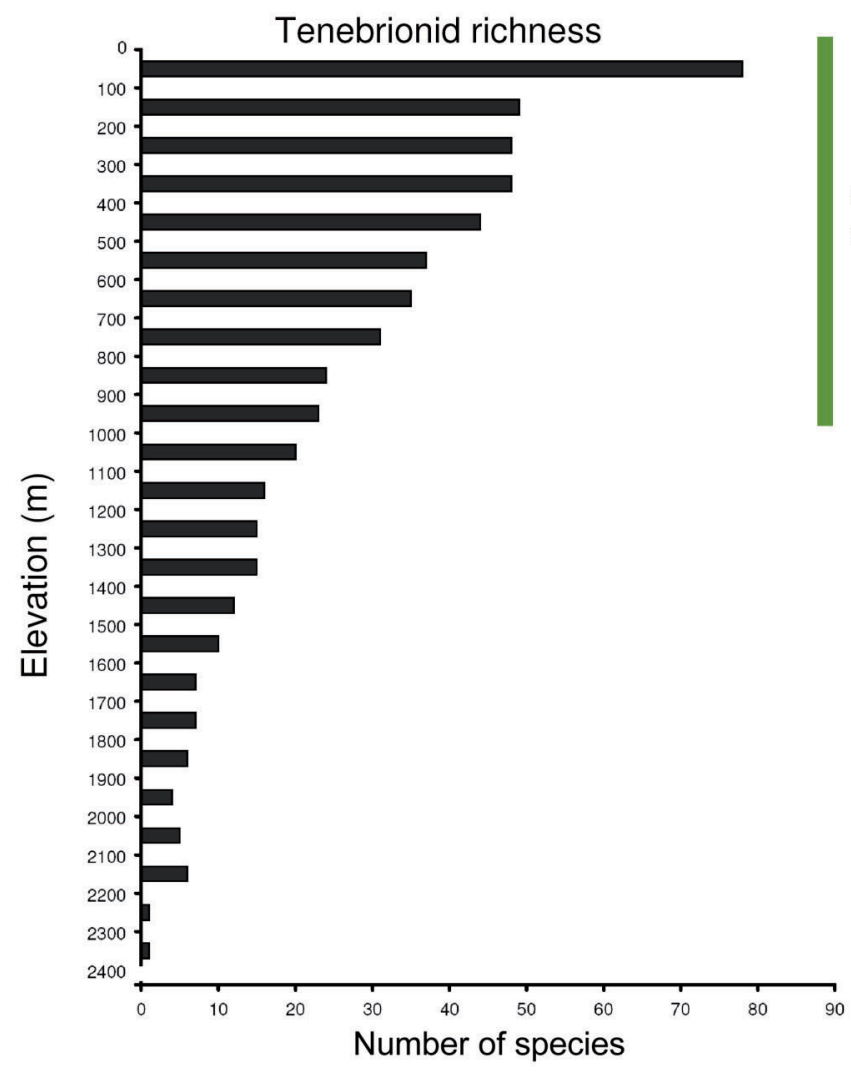

\section{Vegetational Belts}

sclerophyll evergreen vegetation and heliophilic broadleaves

sciaphilous broadleaves

high altitude pastures and grasslands

Figure 1. Variation in tenebrionid species richness along the elevational gradient (left panel) and main vegetational belts (right panel). 
very different from those of all lower belts. These lower belts show however a strong division between a group of belts between 901 and 1500 $\mathrm{m}$ and a second group comprising belts between 0 and $900 \mathrm{~m}$. Within this elevational range, a relatively abrupt change in faunal composition exists between belts from 0 to $300 \mathrm{~m}$ and those between 301 and $900 \mathrm{~m}$. Thus, Simpson's similarity indicates abrupt changes in faunal composition at about 300,1000 and $1700 \mathrm{~m}$. The analysis based on chorotypes (Figure $4 \mathrm{~b}$ ) produced very similar results. The two similarity matrices (Simpson's index and Morisita's index) were correlated (Mantel test $\left.r_{\mathrm{s}}=0.625, \mathrm{P}=0.001\right)$.

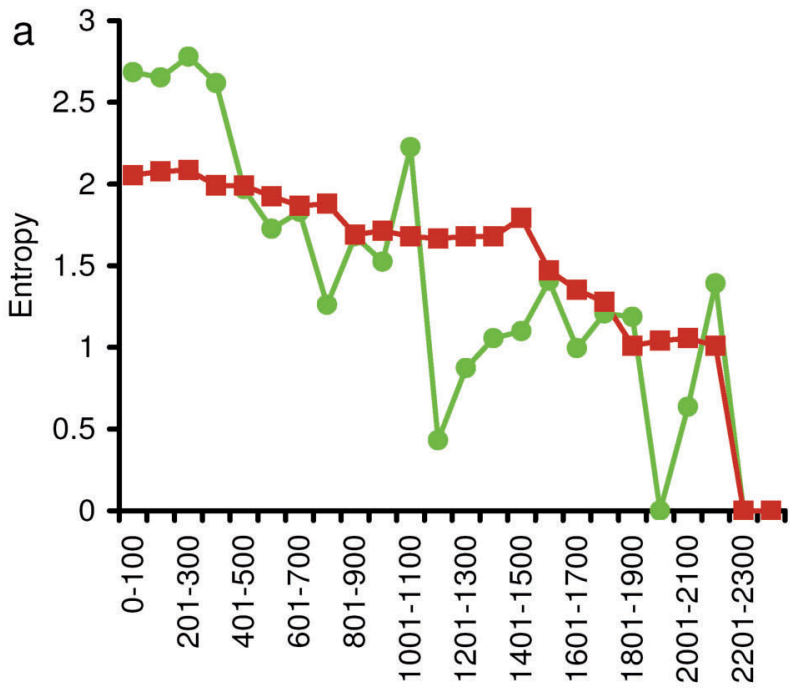

Elevation (m)

\section{Discussion}

Tenebrionid richness declines sharply with elevation, which is an expected pattern for insects that are mostly represented by thermophilic species. Entropy of tenebrionid beetles assemblages roughly decreased with elevation, which indicates that high elevation belts have simplified communities. On the other hand, evenness increased slightly with elevation, which suggests that high elevation areas have smaller, but more balanced communities. This may be a reflection of

Figure 2. Variation in tenebrionid species entropy (a) and evenness (b) along the elevational gradient in Latium based on species com-

position (circles) and chorotype frequencies (squares).

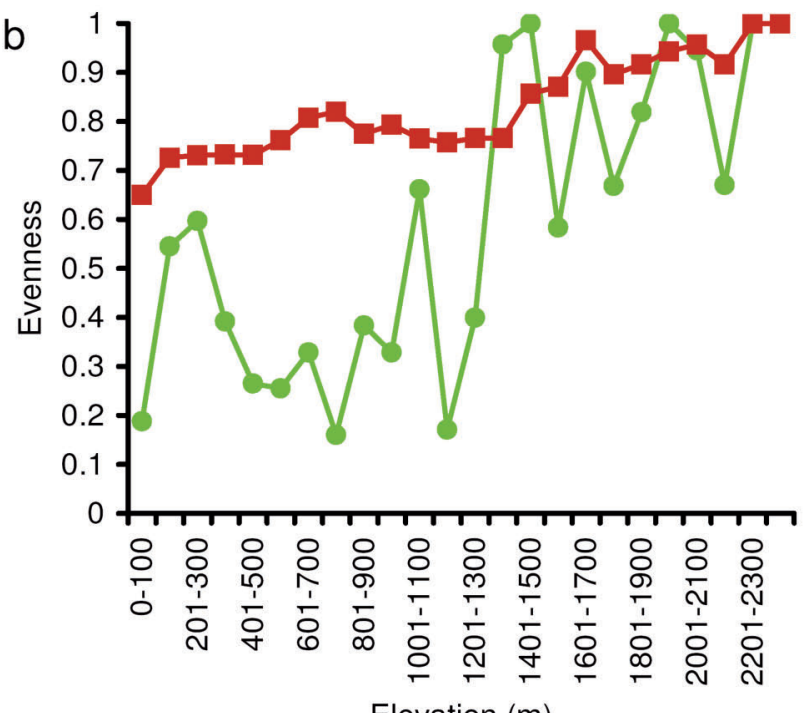

Elevation $(\mathrm{m})$

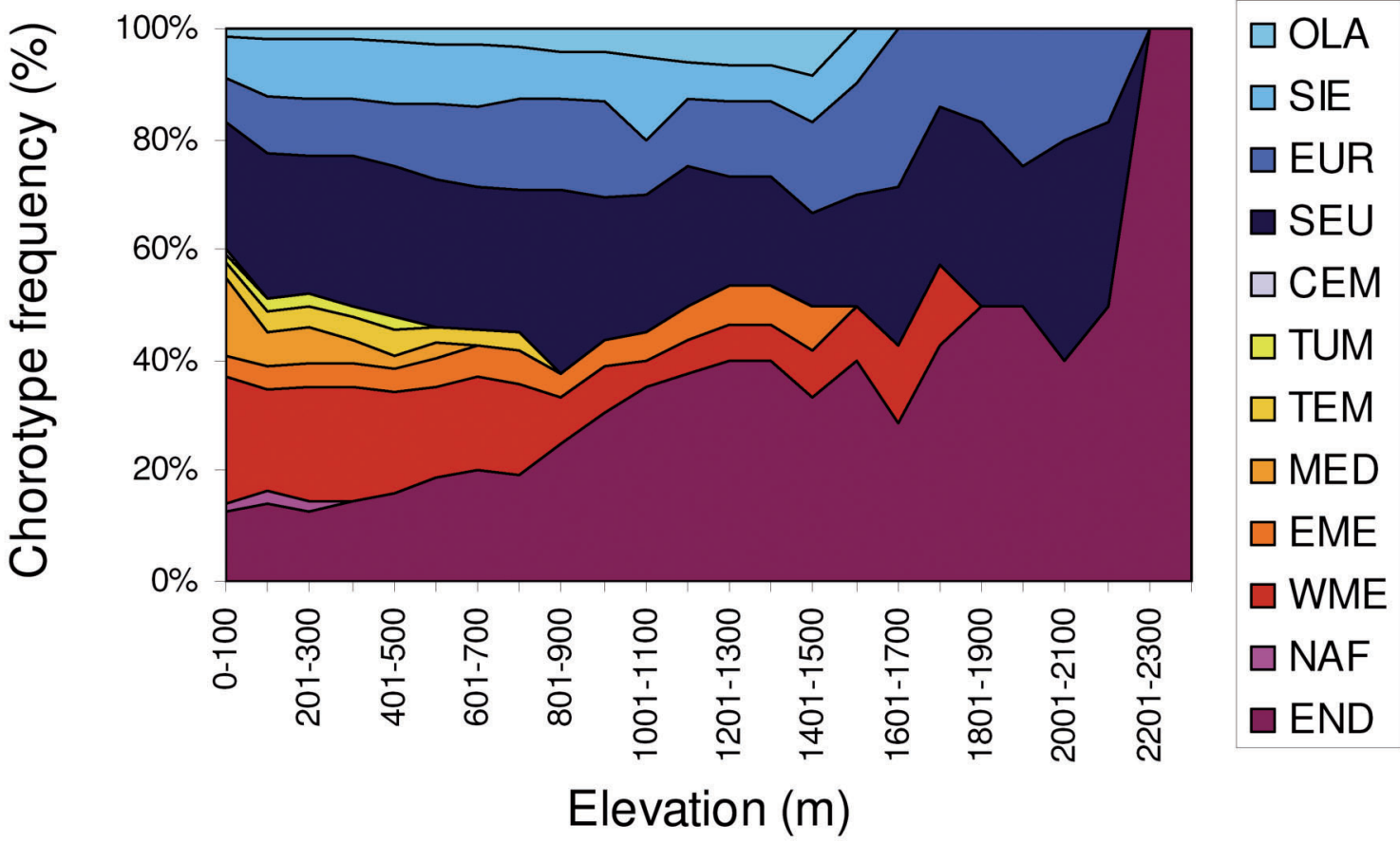

Figure 3. Variation in tenebrionid chorotype composition along the elevational gradient in Latium. Chorotype abbreviations as in Table 1. 
the fact that, at low elevations, communities are more diversified because of the presence of many rare species; at high elevations, most of the species occur with similar abundances. Thus, high elevation assemblages are less diversified, but more balanced than lowland assemblages, in terms of both species and chorological composition.

The prevalence of species with southern chorotypes at lower elevation can be clearly related to the Mediterranean feature of the investigated area. The climate of the study area, favouring species with thermophilous preferences, can be responsible for a high incidence of species with such ranges. As an evidence of this fact, the Mediterranean elements are mostly represented by sand dwelling thermophilous species. However, northern chorotypes (corresponding to mesophilous species) account for about half species composition even at lower elevations. The occurrence of some mesophilous species with northern chorotypes even at low elevations can be related to the presence, in the study area, of lowland hygrophilous/mesophilous forests. Although the current ecological conditions may explain the persistence of species with these different distributional patterns, important past events exerted a strong influence in determining changes in species distributions (Fattorini \& Maltzeff, 2001; Fattorini, 2002b, 2005; Fattorini \& Vigna Taglianti, 2002). Past climates oscillated greatly from the Eocene to post Pleistocene with some periods, such as Pleistocene glacials, being relatively cool and others being warmer or drier in both North America and Europe. Such large-scale climatic fluctuations forced insect populations to change their geographical and elevational distribution (Ciplak, 2008). During cold periods, species adapted to warm-temperate climates retreated into southern localised refugia (mainly situated on the large European peninsulas), while cold-adapted species were favoured in expanding their range in central and southern Europe (Fattorini \& Baselga, 2012; Fattorini \& Ulrich, 2012a,b; Ulrich \& Fattorini, 2013). By contrast, during warm periods, species adapted to temperate-warm climatic conditions expanded over large distances to central and even northern Europe, whereas coldadapted species were driven away to higher latitude and elevation
(Ciplak, 2008; Fattorini \& Baselga, 2012; Fattorini \& Ulrich, 2012a,b; Ulrich \& Fattorini, 2013). The occurrence of many thermophilous species with southern chorotypes among the tenebrionids living in Latium can be related to hypothetical refugial role of Italian coastal areas during Pleistocene glaciations. In fact, the interior portions of continents were generally colder than places nearer the coasts, which could have played the role of refugia thanks to their more temperate climate, especially along the seashore (Fattorini, 2008). The present occurrence of some species with northern chorotypes even at very low elevation can be related to the presence of hygrophilous/mesophilous plant communities even in coastal sites (Fattorini \& Maltzeff, 2001; Fattorini, 2002b, 2005; Fattorini \& Vigna Taglianti, 2002). Dendrophilic tenebrionid species, associated with mesophilous plant communities, probably colonized the coastal areas during glaciations, and, when the climate became drier and warmer, were forced to shift to northern distributions, leaving isolated populations in coastal areas where favourable habitats persisted (Fattorini \& Vigna Taglianti, 2002). The percentage of southern chorotypes declines rapidly with elevation, and no southern species is found over $1800 \mathrm{~m}$. This is clear evidence that only cold-adapted species, with northern (Eurasian) distributions, can survive at high elevations.

Endemic taxa tend to increase with elevation, and they are mostly represented by high elevation populations recognised as subspecies. The most remarkable case is that of Asida pirazzolii, a high elevation species, most frequently encountered over $1500 \mathrm{~m}$. At lower elevation, this species is localised in few places characterised by cold climate. It includes two subspecies: the typical form and the ssp. sardiniensis (in spite of its name, it does not occur in Sardinia). The geographical ranges of these two forms are largely overlapping (Fattorini, 2010). However, they have different elevational ranges, the ssp. sardiniensis being typically encountered at lower elevation than the typical form. Individuals with transitional morphological characters are occasionally found and the systematics of these two forms needs resolution. A similar situation occurs for Colpotus strigosus, an Italian endemic species,

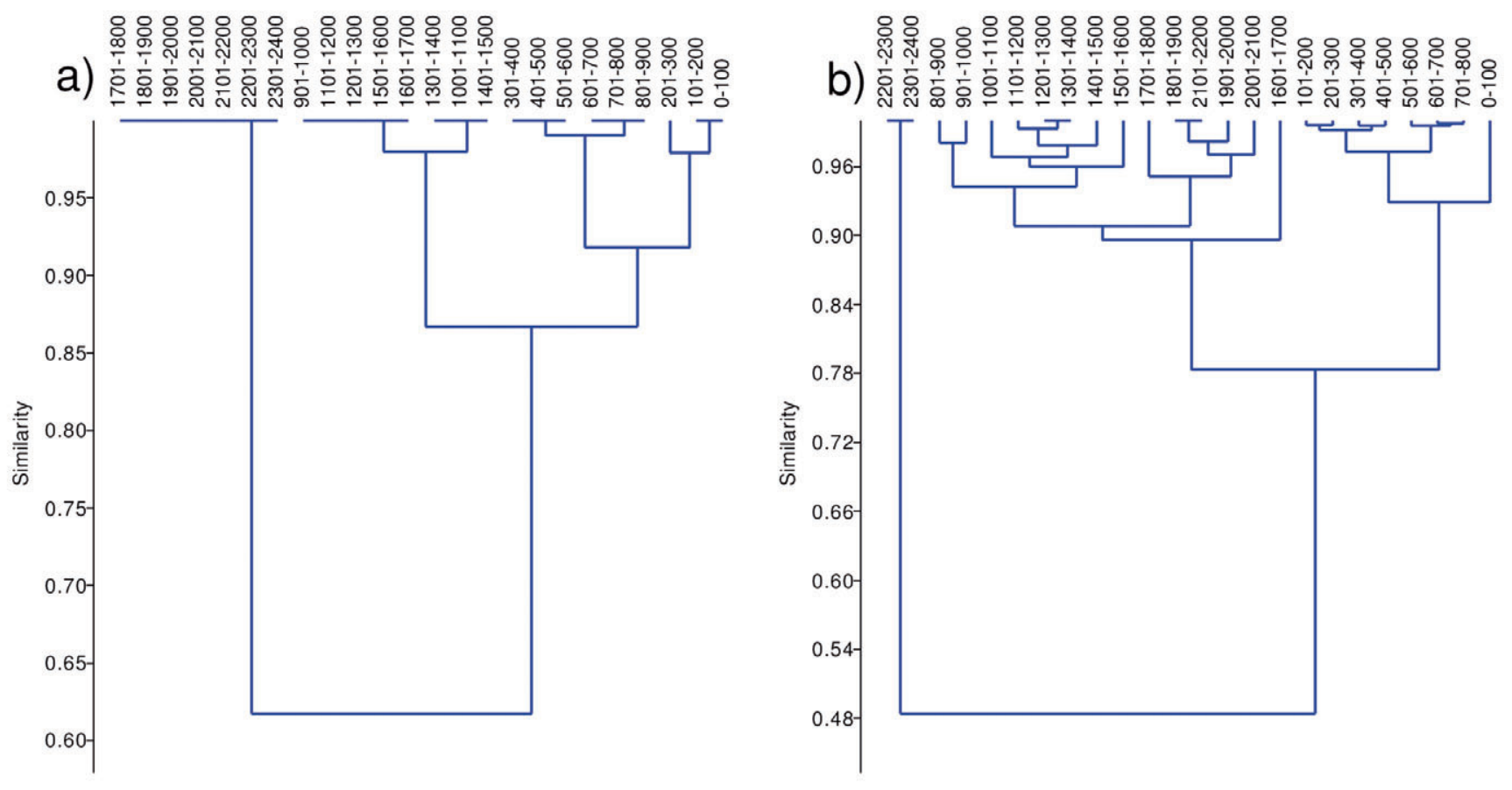

Figure 4. Cluster analyses of elevational belts based on species presence/absence (a, Simpson's index; coefficient of cophenetic correlation: 0.558 ) and chorotype frequency (b, Morisita's index; coefficient of cophenetic correlation: 0.857 ). 
whose nominal form shows a wide distribution, whereas the subspecies ganglbaueri is restricted to high elevation biotopes (>1500 m) (Fattorini, 2010).

In a study on the Scarabaeoidea of the Eastern Mountains of the Iberian Central System, Martin-Piera et al. (1992) compared the zoogeographical composition of two montane areas with a change in elevation of about $500 \mathrm{~m}$. They found a prevalence of species with Mediterranean (sensu lato) chorotypes in the lower area, and a prevalence of species with Sibero-European and endemic distributions in the higher area. They interpreted these results assuming that SiberoEuropean and endemic species colonized the study area during colder periods and were prevented from dispersing toward lower elevations by a climatic discontinuity. This interpretation might also partially be valid for the tenebrionids of Latium. During colder periods, species with northern distributions were favoured in colonizing southern areas, but remained confined to the higher places when the climate ameliorated.

For the tenebrionids of Latium, inter-belt similarity in species composition was strictly correlated with similarity obtained using chorotypes. This indicates that elevation is a factor that strongly selects species' attributes and especially their geographical distribution. Also the maximum evenness observed at highest elevations could be the consequence of population strategies typical of endemic species (Brandmayr, 1991), that results in a more balanced species assemblage pattern.

Traditional zonations of the study area based on vegetational settings identify three main belts: the basal belt (with sclerophyll evergreen vegetation and heliophilic broadleaves: $0-1000 \mathrm{~m}$ ); the montane belt (sciaphilous broadleaves: $800-1800 \mathrm{~m}$ ); and the culminal belt (high elevation pastures and grasslands: 1800-2900 m) (Giacomini \& Fenaroli, 1958; see also Figure 1). This classification well corresponds with similarity in tenebrionid assemblages depicted by cluster analysis based on species distribution and chorotype frequencies, which strongly supports that both current vegetational settings and animal assemblages have been structured in response to some common driving forces, namely the elevational gradient in climatic variables and the past history of the study area.

\section{References}

ADDINSOFT, 2004. XLSTAT 7.5.2. Available from: http://www.xlstat.com/ index.html.

ALIQUÒ V., RASTELLI M., RASTELLI S., SOLDATI F., 2006 - Coleotteri Tenebrionidi d'Italia - CD-ROM Museo Civico di Storia Naturale di Carmagnola, Carmagnola, Italy.

BASELGA A., 2010 - Partitioning the turnover and nestedness components of beta diversity. - Global Ecol. Biogeogr. 19 (1): 134-143.

BASELGA A., 2012 - The relationship between species replacement, dissimilarity derived from nestedness, and nestedness. - Global Ecol. Biogeogr. 21 (12): 1223-1232.

BRANDMAYR P., 1991 - The reduction of methathoracic alae and of dispersal power of carabid beetles along the evolutionary pathway into the mountains. In: LANZAVECCHIA G., VALVASSORI V., (eds), Form and function in zoology. U.Z.I. Selected Symposia and Monographs 5 - Mucchi Editore, Firenze: 363-378

CIPLAK B., 2008 - The analogy between interglacial and global warming for the glacial relicts in a refugium: a biogeographic perspective for conservation of Anatolian Orthoptera. In: FATTORINI S., (ed), Insect ecology and conservation. - Research Signpost, Trivandrum: 135-163.

FATTORINI S., 2002a - Biogeography of the tenebrionid beetles (Coleoptera, Tenebrionidae) on the Aegean Islands (Greece). - J. Biogeogr. 29 (1): 49-67.
FATTORINI S., 2002b - The Tenebrionidae (Coleoptera) of a Tyrrhenian coastal area: diversity and zoogeographical composition. Biogeographia 23: 103-126.

FATTORINI S., 2005 - I Coleotteri Tenebrionidi del Parco Nazionale del Circeo (Italia Centrale) (Coleoptera, Tenebrionidae). - Boll. Ass. Romana Entomol. 60 (1-4): 47-104.

FATTORINI S., 2008 - Ecology and conservation of tenebrionid beetles in Mediterranean coastal areas. In: FATTORINI S, (ed), Insect ecology and conservation. - Research Signpost, Trivandrum: 165-297.

FATTORINI S., 2010 - Use of insect rarity for biotope prioritisation: the tenebrionid beetles of the Central Apennines (Italy). - J. Insect Conservation 14 (4): 367-378.

FATTORINI S., 2013 - Regional insect inventories require long time, extensive spatial sampling and good will. - PLoS One 8 (4): e62118.

FATTORINI S., BASELGA A., 2012 - Species richness and turnover patterns in European tenebrionid beetles. - Insect Conservation Diversity 5 (5): 331-345.

FATTORINI S., MALTZEFF P., 2001 - I Coleotteri Tenebrionidi della Tenuta presidenziale di Castelporziano (Coleoptera, Tenebrionidae). - Boll. Ass. Romana Entomol. 56: 245-300.

FATTORINI S., ULRICH W., 2012a - Drivers of species richness in European Tenebrionidae (Coleoptera). - Acta Oecol. 43: 255-258.

FATTORINI S., ULRICH W., 2012b - Spatial distributions of European Tenebrionidae point to multiple postglacial colonization trajectories. - Biol. J. Linn. Soc. 105 (2): 318-329.

FATTORINI S., VIGNA TAGLIANTI A., 2002 - Ecological and historical factors affecting carabid and tenebrionid communities (Coleoptera Carabidae and Tenebrionidae) in a Mediterranean coastal area. Biogeographia 23: 81-102.

GIACOMINI V., FENAROLI L., 1958 - Conosci l'Italia. La flora. - Touring Club Italiano, Milano.

GRYTNES J.A., VETAAS 0.R., 2002 - Species richness and altitude: a comparison between null models and interpolated plant species richness along the Himalayan altitudinal gradient, Nepal. - Am. Nat. 159 (3): 294-304.

HAMMER Ø., HARPER D.A.T., RYAN P.D., 2001 - PAST: Paleontological Statistics Software Package for Education and Data Analysis. Palaeontologia Electronica 4 (1): 1-9.

HAYEK L.C., BUZAS M.A., 2010 - Surveying natural populations. Quantitative tools for assessing biodiversity. - Columbia University Press, New York.

KOLEFF P., GASTON K.J., LENNON J.J., 2003 - Measuring beta diversity for presence-absence data. - J. Anim. Ecol. 72: 367-382.

KREBS C.J., 1989 - Ecological methodology - Harper \& Row, New York.

LÖBL I., SMETANA A., 2008 - Catalogue of Palaearctic Coleoptera. Vol. 5. Tenebrionoidea. - Apollo Books, Stenstrup.

MANI M.S., 1968 - Ecology and biogeography of high altitude insects. Springer Netherlands, Dordrecht.

MARTIN-PIERA F., VEIGA C.M., LOBO J.M., 199 - Ecology and biogeography of dung-beetle communities (Coleoptera, Scarabaeoidea) in an Iberian mountain range. - J. Biogeogr. 19 (6): 677-691.

MENA J.L., VÁZQUEZ-DOMÍNGUEZ E., 2005 - Species turnover on elevational gradients in small rodents. - Global Ecol. Biogeogr. 14 (6): 539-547.

OLIVERO J., REAL R., MÁRQUEZ A.L., 2011 - Fuzzy chorotypes as a conceptual tool to improve insight into biogeographic patterns. - Syst. Biol. 60 (5): 1-16.

PIZZOLOTTO R., 2009 - Characterization of different habitats on the basis of the species traits and eco-field approach. - Acta Oecol. 35 (1): 142-148.

RAHBEK C., 1997 - The relationship among area, elevation, and regional species richness in Neotropical birds. - Am. Nat. 149 (5): 875902.

ROWE R., 2009 - Environmental and geometric drivers of small mam- 
mal diversity along elevational gradients in Utah. - Ecography 32 (3): 411-422.

SALVATI L., PERINI L., BAJOCCO S., SABBI A., 2012 - Climate aridity and land use change: a regional-scale analysis - Geogr. Res. 50 (2): 193-203.

SAMWAYS M.J., MCGEOCH M., NEW T.R., 2010 - Insect conservation. A handbook of approaches and methods - Oxford University Press, Oxford.

SHI G.R., 1993 - Multivariate data analysis in palaeoecology and palaeobiogeography - a review. - Palaeogeogr. Palaeoecol. 105 (3-4): 199234.

STATSOFT, 2004. STATISTICA (data analysis software system), version 7. Tulsa, OK. www.statsoft.com.

ULRICH W., FATTORINI S., 2013 - Longitudinal gradients in the phylo- genetic community structure of European Tenebrionidae (Coleoptera) do not coincide with the major routes of postglacial colonization. - Ecography 36 (10): 1106-1116.

VIGNA TAGLIANTI A., AUDISIO P., BIONDI M., BOLOGNA M.A., CARPANETO G.M., DE BIASE A., FATTORINI S., PIATTELLA E., SINDACO R., VENCHI A., ZAPPAROLI M., 1999 - A proposal for a chorotype classification of the Near East fauna, in the framework of the Western Palearctic region. - Biogeographia 20: 31-59

WU Y., YANG Q., WEN Z., XIA L., ZHANG Q., ZHOU H., 2012 - What drive the species richness patterns of non-volant small mammals along a subtropical elevational gradient? - Ecography 36 (2): 1-12.

ZUNINO M., ZULLINI A., 1995 - Biogeografia. La dimensione spaziale dell'evoluzione. - Casa Editrice Ambrosiana, Milano. 